\title{
AN APPLICATION OF MODIFIED WEIGHTED NÖRLUND MEANS TO A SERIES ASSOCIATED WITH FOURIER SERIES
}

\author{
PREM CHANDRA
}

\author{
Date of Receiving : $\quad$ 20.08. 2014 \\ Date of Revision : $\quad$ 27.12. 2014 \\ Date of Acceptance : 28.12 .2014
}

\begin{abstract}
In this paper, we apply modified absolute Nörlund means with weights(Das [15]) to study absolute Nörlund summability of Fourier series with multipliers and obtain some necessary and sufficient conditions, imposed upon the generating function of Fourier series, as well as best possible absolute summability multipliers in certain sense. As a consequence, we not only get some new results but some results, which improve earlier results, have also been obtained.
\end{abstract}

\section{DEFINITIONS AND NOTATIONS}

Let $\left(p_{n}\right)$ be a sequence of constants such that

$$
P_{n}=p_{0}+p_{1}+p_{2}+\ldots+p_{n} \neq 0 \text {, for } n \geq 0
$$

and let $\lambda=\left(\lambda_{n}\right)$ be a given positive sequence. Then modified Nörlund mean with weight $\lambda=\left(\lambda_{n}\right)$ of $\sum_{n=0}^{\infty} \omega_{n}$ is defined by

$$
d_{n}=\frac{1}{P_{n} \lambda_{n}} \sum_{k=0}^{n} p_{n-k} \lambda_{k} \omega_{k}
$$

If the series $\sum_{n=0}^{\infty} d_{n}$ converges to $s$, we say that $\sum_{n=0}^{\infty} \omega_{n}$ is summable by modified Nörlund mean with weight $\lambda=\left(\lambda_{n}\right)$ or summable $\left(N^{\prime}, p_{n}, \lambda_{n}\right)$ to $s$. And if

$$
\sum_{n=0}^{\infty}\left|d_{n}\right|<\infty
$$

then $\sum_{n=0}^{\infty} \omega_{n}$ is said to be absolutely summable by modified Nörlund mean of weight $\lambda=\left(\lambda_{n}\right)$ or summable $\left|N^{\prime}, p_{n}, \lambda_{n}\right|$. For this, see Das [15].

2010 Mathematics Subject Classification. 42A24, 42A45, 40F05, 40G05, 40G99.

Key words and phrases. Multipliers, Modified absolute Nörlund summability, Generalized harmonic summability.

Communicated by. L.K. Vashisht 